\title{
REFLEXÃO SOBRE A IMPORTÂNCIA DA LINGUÍSTICA DA VARIAÇÃO E MUDANÇA NA FORMAÇÃO DE PROFESSORES DE LÍNGUA MATERNA
}

RESUMO: Pretendo, neste trabalho, retomar uma reflexão sobre a importância dos conhecimentos sobre variação e mudança linguísticas na formação de professores de língua materna, partindo do princípio de que os saberes científicos são pressupostos da prática pedagógico-didática. Nesta perspetiva, sublinharei a relevância informativa e formativa dos conhecimentos sobre variação e mudança linguísticas para atingir metas e realizar objetivos relacionados com o ensino da variação da língua e da sua origem e evolução.

A compreensão dos fenómenos de variação e mudança permite a consciencialização do fluir da língua no tempo e contribui para a compreensão de que a variação de uma língua é uma dimensão intrínseca e consubstancial do seu funcionamento e da sua historicidade. Os traços de sincronias do passado são fruto de uma configuração linguística e referencial diferentes, transversais a todos os níveis de análise: a nível da fonética, da morfologia, do léxico, mas também da conetividade sequencial e da ordem sintática.

Acresce ainda considerar a inseparabilidade entre o texto e o seu contexto: o sentido do texto antigo depende de referentes contextuais que se alteraram substancialmente e é preciso ter consciência dessa alteração. A partir da análise de fenómenos da história do português, tentarei, portanto, demonstrar a inseparabilidade entre as dimensões informativa e formativa da reflexão sobre variação e mudança linguísticas.

PALAVRAS-CHAVE: História do Português, ensino da língua materna, variação linguística 
ABSTRACT: In this paper, I intend to return to a reflection on the importance of knowledge about linguistic variation and change in the training of native language teachers, assuming that scientific knowledge is a presupposition of pedagogical-didactic practice. From this perspective, I will underline the informative and formative relevance of knowledge about language variation and change in order to achieve goals and accomplish objectives related to the teaching of language variation and its origin and evolution.

Understanding the phenomena of variation and change allows awareness of the flow of language over time and contributes to the understanding that the variation of a language is an intrinsic and consubstantial dimension of its functioning and its historicity. Synchrony traces of the past are the result of a different linguistic and referential configuration, transversally at all levels of analysis: in phonics, morphology, lexicon, but also in sequential connectivity and syntactic order.

In addition, the inseparability between the text and its context must be considered: the meaning of the old text depends on contextual referents that have changed substantially and it is necessary to be aware of this change. From the analysis of phenomena in the history of Portuguese, I will attempt to demonstrate the inseparability between the informative and formative dimensions of reflection on linguistic variation and change.

KEYWORDS: portuguese history, mother tongue teaching, linguistic variation

\section{1 - Introdução}

Pretendo, neste trabalho, retomar uma reflexão (cf. Barros 1997) sobre a importância dos conhecimentos sobre variação e mudança linguísticas na formação de professores de língua materna, partindo do princípio de que os saberes científicos são inerentes à condição de se ser professor, são pressupostos da prática pedagógico-didática. Não se pode conceber uma adequada prática pedagógica sem um conhecimento profundo do objeto de ensino. Nesta perspetiva, sublinharei a relevância informativa e formativa dos conhecimentos sobre variação e mudança linguísticas para atingir metas e realizar objetivos relacionados com o ensino da variação da língua e da sua origem e evolução.

Começando pela dimensão informativa: são diversos os objetivos e conteúdos programáticos do ensino da língua materna que estão diretamente relacionados com a variação da língua, sendo referidos explicitamente aspetos como a origem e a evolução da língua postos em evidência pelo 
estudo de textos da produção literária e cultural de períodos históricos do passado.

Mas, para além desta dimensão informativa, é muito relevante o papel formativo do estudo da História da Língua: a compreensão dos fenómenos de variação e mudança permite a consciencialização do fluir da língua no tempo e contribui para a compreensão de que a variação de uma língua é uma dimensão intrínseca e consubstancial do seu funcionamento e da sua historicidade. Tal consciencialização implica: o conhecimento da evolução linguística; a compreensão de fenómenos concretos dessa evolução; a consideração das fases de expansão/propagação das mudanças; a regularidade da variação. Conjugando esta perspetiva formativa com a perspetiva informativa, o estudo histórico da língua conduz ao conhecimento de fenómenos específicos de variação histórica, determinados do ponto de vista espacial e temporal - os que concernem à Língua Portuguesa tendo como consequência um melhor conhecimento dessa língua nos seus diferentes períodos.

A fundamentação teórica deverá ser sempre a base de uma prática pedagógica reflexiva. Vou referir alguns aspetos concretos que são afetados pela aquisição de competências relacionadas com uma formação no âmbito da linguística da variação e mudança. Uma formação que confere ao professor de língua materna uma capacidade de tratamento crítico do testemunho, particularmente de sincronias do passado - o estudo de textos do passado; que apura a sua sensibilidade a tradições discursivas diferentes, a tipologias diversificadas dos textos/discursos; que desenvolve a sua capacidade de perspetivar as irregularidades/exceções como resultados de um processo evolutivo; que lhe faculta o conhecimento da variação não só como evolução linguística mais remota mas também como mudança recente ou ainda em curso. Trata-se, pois, de uma competência diversificada que poderá interferir de formas muito variadas na prática de ensino.

\section{2 - A análise de textos do passado}

Passo a focar mais desenvolvidamente a questão da análise de textos do passado, em que o conhecimento da linguística histórica permite a perceção da variação interna de uma sincronia do passado e dos fenómenos de diversificação e de evolução em curso que se verificam nesses cortes, abstratos, que são as sincronias. A análise não deverá confinar-se a uma procura de curiosidades etimológicas (lexicais ou fonéticas); deverá ser mais ampla, tentando abranger todo o sistema de uma sincronia do passado, relacionando-o com a múltipla diversificação que se observa também no português moderno. 
Continua a haver, no ensino atual do português língua materna, espaço para a análise de textos do passado e da língua de outras sincronias. As rubricas que dizem respeito à historicidade da língua são sobretudo suscitadas no âmbito do estudo de produções linguísticas como objeto histórico - textos literários - em relação aos quais tem de haver uma visão diacrónica, tem de estar assegurada a capacidade de distinguir e caracterizar épocas e períodos e de situar no tempo as obras e os autores. É de referir a presença nos programas de obras do período clássico - de Gil Vicente e de Camões - e ainda, na área de estudos de Línguas e Humanidades, textos de um período mais antigo, nomeadamente os da lírica trovadoresca medieval.

O estudo dos textos medievais e renascentistas constitui, sem dúvida, um momento privilegiado da aula de português para a reflexão sobre a origem e evolução da língua: para além da sua representatividade literária, devem também ser encarados como testemunhos linguísticos de estados de língua afastados no tempo.

No caso do português, a língua dos textos de outras sincronias é, ou parece ser, perfeitamente inteligível. A prova de que não se considera a dificuldade de apreensão do sentido dos textos é, por exemplo, a quase inexistência de boas traduções dos textos medievais portugueses em português moderno. De facto, apesar de toda a evolução sofrida, pensa-se que há ainda uma transparência do sentido global dos textos, apesar da dificuldade, maior ou menor, em entender o léxico da época.

\section{1 - O léxico histórico}

No que diz respeito ao léxico, é unanimemente reconhecida a necessidade de 'traduzir' elementos 'específicos' e 'diferentes', ou seja, é geralmente aceite a opacidade, pelo menos parcial, desses textos. Fala-se de, e estuda-se, o léxico 'arcaico' da lírica trovadoresca e o léxico 'clássico' (mas por vezes também arcaizante) de Gil Vicente e de Camões. Em relação aos textos destes autores quinhentistas, são também apontados arcaísmos medievais (mais na obra vicentina, menos na de Camões) que destoam do todo clássico com laivos de modernidade que os autores representam. Mas talvez o que se designa por arcaísmo não seja mais do que a manifestação da variação em curso, da diversificação linguística patente nos usos linguísticos da época.

Gil Vicente é considerado um autor situado entre o português medieval e o clássico, sendo mesmo a sua obra classificada com uma baliza cronológica entre esses dois períodos. Basta consultar a obra de Paul Teyssier sobre a língua de Gil Vicente (Teyssier 2005) para verificar a coexistência de formas tipicamente medievais, como por exemplo: as terminações dos particípios passados em -udo, como teudo, sabudo, temudo; as terminações verbais da 5. ${ }^{\text {a }}$ pessoa em-ades, -edes, -ides, como em amades, fazedes, partides; a 1. ${ }^{\text {a }}$ pessoa 
irregular de alguns verbos, como arço, nasco, moiro; os possessivos femininos átonos ma ta $\mathrm{s} a$, entre outras. Mas essas formas coexistem com aspetos que irão caracterizar o português moderno. Assim, observamos o sistema da deixis espacial já a três dimensões e a presença de inúmeras palavras inovadoras de origem latina clássica. Há mesmo autores que defendem que as obras mais tardias de Gil Vicente apresentam uma linguagem mais clássica e um estilo aristocrático que se afasta dos traços tradicionais e populares das obras iniciais. Mas é preciso não esquecer que na dramaturgia vicentina surgem em cena, e em diálogo, personagens que utilizam socioletos e dialetos diversos que as caracterizam como 'tipos' sociais e/ou regionais. Por exemplo, os 'rústicos' vicentinos atualizam dialetos setentrionais, já claramente desprestigiados, e algumas formas seriam sentidas como provincianas, afastadas dos usos-padrão inovadores. Em alguns casos, as falas das personagens mantêm usos vindos de sincronias anteriores que naturalmente se prolongam e coexistem com novas soluções e usos linguísticos inovadores de uso recente no idioma. Todos eles convivem no português quinhentista. Numa mesma peça-Auto da Alma - um diabo usa a forma tradicional $\operatorname{arço~(Gil~Vicente~s/d.:~verso~525),~e~a~alma~usa~}$ a forma inovadora arda (Gil Vicente s/d.: verso 75). Os exemplos de formas classificadas como regionalismos, arcaísmos e plebeísmos integram, afinal, a língua da sua época. Tal como acontece em todos os estados de língua, havia diversificação linguística no período quinhentista e ela está bem patente nos textos de Gil Vicente e, em menor grau, nos de Camões.

\section{2 - Aspetos da configuração fonética e fonológica do português de} sincronias do passado e da sua evolução

Há também alguns aspetos característicos a nível da configuração fonética/ fonológica do português de sincronias do passado, que são completamente opacos para o leitor dos nossos dias. Há subsistemas que, tendo sofrido evolução histórica, são apreendidos de acordo com a sua realização moderna sem atentar na sua especificidade noutras sincronias. A evolução não foi acompanhada de qualquer alteração ortográfica. É o caso, por exemplo, dos subsistemas das sibilantes e das fricativas palatais cuja configuração era mais complexa do que nas sincronias modernas do português. O mesmo se pode dizer dos fenómenos de elevação, centralização e redução vocálicas no que respeita ao vocalismo átono, que também não estão registados na ortografia oficial portuguesa. Esta perpetua, portanto, sistemas linguísticos históricos, hoje desaparecidos pelo menos no uso padrão, embora continuem presentes em algumas variedades regionais do português. O leitor contemporâneo comum tende a ler os textos do passado atualizando o sistema fonológico do português contemporâneo, sem se aperceber de certas especificidades da pronúncia antiga ou renascentista, uma vez que a grafia é interpretada pela correspondência grafemas-fonemas 
do português atual. E não distingue, por exemplo, entre sem e cem, paço e passo, dada a redução do sistema de sibilantes de quatro para dois fonemas. A grafia dos textos de sincronias do passado, parecendo transparente, é, de facto, opaca porque o leitor moderno está condicionado pela correspondência grafema-fonema atual. Só o conhecimento do sistema do passado esclarece os casos de homofonia anteriormente referidos.

\section{3 - Aspetos de evolução semântica}

É também aqui oportuna a referência à evolução semântica sofrida ao longo da história por diversos vocábulos, mesmo quando se conservam no português atual. Termos como guisado, catar, freesta, adubar, viçoso ou salvar vão manter-se no léxico, mas adquiriram um sentido e uso diversos. A título de exemplo: seria inimaginável no português contemporâneo adjetivar senhoras com a expressão bem guisadas ou designar uma larga abertura como uma fresta, como era comum no português antigo: "muitas damas mui bem guisadas"; "Veede-lo: stá aaquela freesta falando com dom Galvam" (A Demanda do Santo Graal. Ed. Magne 1955: 98). O léxico gramatical arcaico e clássico manifesta também sentidos/usos diferentes. Uma conjunção de uso multifacetado como $c a$ pode apresentar três sentidos: $c a$ conjunção causal (< quia) de uso muito mais frequente e desenvolto do que porque nas sincronias do passado; $c a$ conjunção comparativa ( $<$ quam) e completiva. Observem-se os seguintes exemplos: "ca teúdo soom de vos fazer serviço em tôdalas cousas que eu poder", "melhor cavaleiro ca vos non", "viu ca se avia de partir dele” (A Demanda do Santo Graal. Ed. Magne 1955: 99).

\section{4 - Evolução fonética e irregularidade morfológica}

O conhecimento da evolução da língua pode ainda revelar que o que se apresenta na sincronia atual como exceção, como irregularidade morfológica, pode ser resultante de fenómenos de evolução, como acontece no caso do plural das palavras terminadas em -am, -om -ão. A observação de diferentes terminações nasais que posteriormente irão convergir para -ão /ã̄/ esclarece o problema da flexão de número, que é irregular no português moderno: can /ã// cães; leon /õ// leões /õ es/; mão /ã o// mãos. Um singular por convergência - três plurais por evolução fonética - sinérese (ditongação):

\begin{tabular}{|c|c|c|}
\hline Singular $\quad$-ãũ & Plural & -ãĩ; õĩ e ãũ \\
\hline can /ã/ > cão & cães & -ã̃̃ \\
\hline leon /õ/ > leão & leões & -õ̃ \\
\hline mão /ã o/ > mão & mãos & -ãũ \\
\hline
\end{tabular}

TABELA 1 - Plural das palavras terminadas em -ão 
Igualmente, a flexão de número dos vocábulos terminados em -1 apresenta plurais diversos:

\begin{tabular}{|l|l|}
\hline Singular -1 & Plural -aj; ej; cj; oj; uj \\
\hline Dedal & Dedais \\
\hline Fácil & Fáceis \\
\hline Fiel & Fiéis \\
\hline Cruel & Cruéis \\
\hline Sol & Sóis \\
\hline Azul & Azúis \\
\hline
\end{tabular}

TABELA 2 - Plural das palavras terminadas em -1

A análise destes casos esclarece também a fisionomia do português contemporâneo com uma multiplicidade de ditongos de formação moderna - orais e nasais - desconhecidos nas restantes línguas românicas. Todos resultantes de um mesmo fenómeno histórico, idiossincrático do português: a síncope de -n- e de -1- intervocálicos.

\subsection{1 - Metafonia, alternância vocálica e irregularidade na flexão nominal e verbal}

Mas há outros casos de evolução linguística com consequências na configuração morfológica. Observam-se alternâncias vocálicas na morfologia que resultam de fenómenos de evolução por metafonia, como no caso da flexão de género e número com elevação da vogal tónica (novo-novos, novonova). Além da distinção por morfemas, há também alternâncias vocálicas a coadjuvar essa distinção:

masculino /-o/ novo vs feminino /-כ/ : nova

singular -Ø novo, forno, miolo vs plural /-כ/ + -s novos; fornos; miolos

Trata-se de um fenómeno vocálico assimilatório, de metafonia.

Há ainda um outro caso interessante de evolução por fenómeno de metafonia (alteração /elevação da vogal tónica) que se verifica na flexão verbal em que, nas formas de génese, a presença de uma semivogal inflexionou o timbre da vogal - trata-se de uma influência assimilatória. O resultado foi a criação de uma alternância no radical do verbo na flexão de tempo, ou de pessoa, ou de modo, como pode observar-se nos seguintes exemplos: 


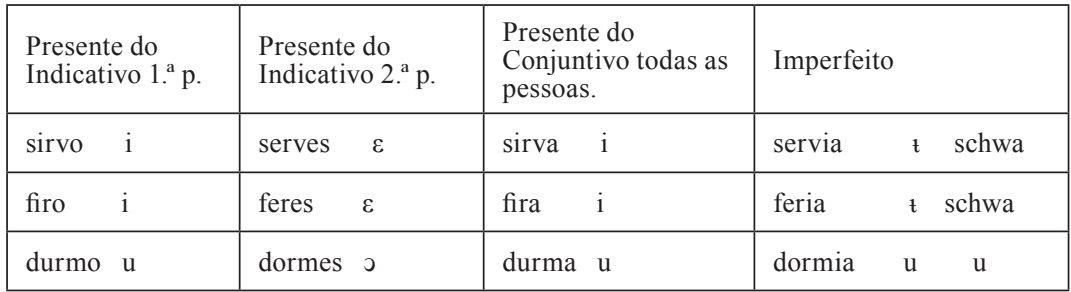

\begin{tabular}{|l|l|}
\hline 1. ${ }^{\text {p }}$. Perfeito & 3. p. Perfeito \\
\hline pude u & pôde o \\
\hline fiz i fez e \\
\hline
\end{tabular}

TABELA 3 - Alternâncias vocálicas na flexão verbal

Observam-se também evoluções por metafonia nos paradigmas dos pronomes: ainda sem metafonia até ao português clássico como todo (= tudo), esto, esso, aquelo ( $=$ isto, isso, aquilo).

\section{5 - Evolução fonética e regularização analógica}

Merecem referência os casos da diferente evolução da 1 . $^{a}$ pessoa do presente do indicativo e o paradigma do presente do conjuntivo de certos verbos em contraste com as restantes formas do verbo: arço, arça, arças, mas ardes, arde, etc; peço, peça, peças, mas pedes, pede, etc; meço, meça, meças, mas medes, mede, etc; ouço, ouça, ouças, mas ouve, ouves, etc. As 1. ${ }^{a}$ s pessoas do singular do presente do indicativo, como arço, sofreram uma regularização analógica a partir do paradigma do verbo, enquanto noutros casos a ação da analogia não se efetivou e a regularização não se verificou, como em ouço, meço, peço, perco (ouvo, medo, pedo, perdo seriam as formas analógicas que por vezes são atualizadas na linguagem infantil). A presença da forma $\operatorname{arço~(=~ardo)~em~textos~do~passado~ajuda,~então,~a~}$ esclarecer a presença das formas excecionais/irregulares que persistem no português moderno.

A alternância nas formas do paradigma do verbo pode sofrer analogia $(*)$ ou conservar-se:

\begin{tabular}{|l|l|l|}
\hline 1. ${ }^{\text {p }}$. Presente Indicativo & Presente Conjuntivo & restantes formas \\
\hline arço $>$ *ardo & arça $>*$ arda, *ardas, *arda & ardes, arde, ardemos, etc. \\
\hline ouço $(*$ ouvo $)$ & ouça, ouças, ouça... & ouves, ouve, ouvimos, ... \\
\hline peço $(*$ pedo $)$ & peça, peças, peça... & pedes, pede, pedimos... \\
\hline
\end{tabular}




\begin{tabular}{|l|l|l|}
\hline meço $(*$ medo $)$ & meça, meças, meça... & medes, mede, medimos... \\
\hline nasco ${ }^{*}$ nasço & nasca $>$ *nasça & nasces, nasce, nascemos... \\
\hline Perco $(*$ perdo $)$ & perca, percas, perca... & perdes, perde, perdemos... \\
\hline moiro $>$ *morro & moira $>$ *morra & morres, morre, morremos. \\
\hline
\end{tabular}

TABELA 4 - Evolução de formas verbais irregulares com ou sem ocorrência de analogia

No que diz respeito à flexão verbal, podem ser ainda referidas outras evoluções, como o apagamento semântico sofrido por certos verbos na sua gramaticalização como verbos auxiliares: ter em vez de haver. Esse conhecimento ajuda a compreender, por exemplo, a recategorização em curso do verbo ir como verbo auxiliar da construção das formas do futuro.

O contacto com textos em que são ainda visíveis momentos anteriores à evolução que conduz à irregularidade pode permitir uma melhor compreensão de alguns traços da atual configuração do português. O estudo destes fenómenos de evolução ajuda a perspetivar o próprio conceito de exceção e de regularidade/irregularidade.

\section{3 - 'Opacidade' no estudo de textos do passado. A relação entre evolução linguística e a ortografia}

Há também alguns aspetos que o leitor moderno não capta, como vimos, porque a ortografia oficial portuguesa não traduz o sistema fonológico atual, conservando, em parte, o sistema do português arcaico e clássico. Então, questionar a ortografia dos textos do passado equivale a consciencializar o sistema fonológico do português de sincronias do passado e a levantar uma série de fenómenos de evolução fonética que conduziram ao português atual. A observação de exemplos pode levar à consciencialização de fenómenos de não correspondência entre fonema e grafema na ortografia oficial portuguesa e à perceção da evolução fonética do período antigo até aos nossos dias. Pode mostrar como se juntam ao critério da pronúncia (manter ou não o $c t, p t, c c$, $p c ̧$ ) o critério da tradição (ameaça, abolir grafadas com $e$ e $o$, sem assinalar o fechamento da vogal) e o da etimologia (conservação do $h$, das grafias $x$ e $c h$; das diversas grafias $-s,-s-, z$, $c$ e $s s$ - para duas sibilantes; do $j$ e do $g$ ).

\section{4 - A variação histórica e a variação em sincronia}

A diacronia ajuda a esclarecer a sincronia, desenvolvendo competências para uma melhor consciencialização da variação em sincronia e da sua relação com a variação histórica. 
Comparando diferentes variedades modernas da língua e perspetivando esses usos diferenciados em relação com diferenças de percurso evolutivo, verifica-se que há atualmente numerosos casos de conservação de usos do passado nas diferentes variedades do português. Por exemplo, a norma do português brasileiro não sofreu alteamento das vogais átonas, sendo neste aspeto muito conservadora. A realização de $o, e$, e $a$ com timbre menos fechado conserva a realização medieval e renascentista dessas vogais ${ }^{1}$. Igualmente, a conservação de /e/ átono final e pretónico realizado como / $\underline{1}$ / (menos elevado) em formas como fizesti, sinhor, milhor, que caracteriza algumas variedades regionais do português, aproxima-se de pronúncias do passado. O mesmo acontece com a pronúncia, sobretudo minhota, do/ã/nasal sem elevação: $c / \tilde{a} / m p o$, $/ \tilde{a} / n d o$. E podem referir-se outras variedades diatópicas do português que exibem fenómenos de conservadorismo, como a realização da africada / $/ \mathfrak{g} /$ em chamar, cachopa, ou a realização do ditongo /ow/ / / $\boldsymbol{\alpha w} /$ em sou, andou, face à monotongação em /o/ da norma padrão: sô, andô; ou as terminações nasais em /ã/ como em bençã; ou em /õw/, $/ \tilde{\mathrm{u}} /$ ou $/ \mathrm{u} /$ como em mõu (mão), num (não), fizerum (fizeram), andu (andam) e ficaru (ficaram); ou ainda a realização regional das sibilantes ápico-alveolares (o chamado $s$ beirão) que constitui a conservação de um traço do português antigo face à realização pré dorso-alveolar da atual norma-padrão.

No âmbito da observação de fenómenos de conservadorismo, qualquer tentativa de eventual reconstituição da leitura em português antigo/renascentista passará pelo recurso à pronúncia ainda hoje viva de variedades de áreas dialetais conservadoras, confirmando a estreita relação entre a história da língua e a variação em geral. Claro que o problema da realização do português antigo - e das suas fronteiras - é uma questão algo nebulosa, sobretudo no que respeita à localização da fronteira sul do primitivo Galego-Português, que serve de teto ao português moderno (cf. Cardeira 2005). De facto, o território entre Douro e Mondego é atravessado por um feixe de isófonas que separa os dialetos portugueses setentrionais dos meridionais, revelando a prolongada instabilidade e os movimentos de populações que, na sequência de sucessivos ermamentos e repovoamentos, provocaram tais fraturas linguísticas. Mas, em termos genéricos, é possível aproximar a pronúncia do português antigo da de variedades ainda existentes.

\footnotetext{
${ }^{1}$ A este respeito, é muito claro o testemunho dos gramáticos quinhentistas. Fernão de Oliveira descreve uma língua com vogais abertas, mesmo em sílaba átona.
} 


\section{5 - A abordagem dos testemunhos do passado linguístico pela perspetiva do 'estranhamento' - consciencialização das diferenças em todos os níveis da análise}

Os traços de sincronias do passado são fruto de uma configuração linguística e referencial diferentes. E é necessário encarar essas diferenças como transversais a todos os níveis de análise. Tenho vindo a referir, até aqui, aspetos específicos a nível da fonética, da morfologia e do léxico. Mas é preciso ter também em conta aspetos da conetividade sequencial, como a ordem sintagmática: há predominância da parataxe e uma frequência elevada de uso da conjunção $e$, num marcado polissíndeto; também surgem muito frequentemente construções com morfemas correlativos que no português moderno só se conservam nas disjuntivas. Os textos antigos apresentam, com alguma recorrência, a ordem com posposição do sujeito: OVS. O caráter não marcado das construções com o sujeito em posição pós-verbal em textos em prosa e em verso mostra que esta estruturação das construções não é resultado de um fenómeno de extraposição do sujeito, mas pelo contrário era a ordem normal e até frequente na língua ${ }^{2}$. Também na coesão interfrásica há especificidade, dado o inventário diferente de conjunções e as funções diferentes de algumas conjunções que sofreram fenómenos de gramaticalização.

Acresce ainda considerar a inseparabilidade entre o texto e o seu contexto: pode haver o risco de não se perceber o sentido do texto antigo pelo facto de os referentes contextuais se terem alterado substancialmente. É preciso ter consciência dessa alteração para ser possível captar a especificidade dos textos antigos como testemunhos de um passado linguístico e cultural.

$\mathrm{Na}$ análise de textos na aula de língua materna o professor recorre frequentemente a elementos de coesão e de coerência que os alunos já dominam; mas em relação a textos de sincronias do passado é mais problemático o recurso quer à competência textual quer ao 'conhecimento do mundo'. Em relação a estados de língua do passado é difícil utilizar esse conhecimento e por isso é necessário fazer a reconstituição de um estado de língua, marcando-o pela diferença a todos os níveis em relação à sincronia atual.

Como vimos em relação ao léxico, o reconhecimento do significado de muitas palavras não é pleno, mesmo que ainda existam em português. É fácil apercebermo-nos da evolução semântica observando as palavras em contexto. Tomemos o exemplo de direito: o significado deste adjetivo em textos até ao século XVI era duplo; significava (1) retilínio e (2) algo

\footnotetext{
${ }^{2}$ Como explica Martins, trata-se de uma característica da gramática do português antigo (2003: 287-288).
} 
imediato temporal ou espacial (direto). Assim, a Rua Direita que existe no burgo medieval de muitas cidades portuguesas era uma ligação imediata e sem interrupções, direta, entre dois pontos da cidade. A entrada na língua da palavra direto, importada do latim no século XVI, faz a palavra direito perder parte do seu significado. Ocorre frequentemente este fenómeno no caso das palavras designadas como divergentes. Só nos damos conta do caráter alatinado que algumas palavras tinham na época quando confrontados com textos de períodos diferentes.

Nos textos quinhentistas, o que se designa por vezes como regionalismos, arcaísmos, plebeísmos, são manifestações da natural diversificação da língua da época que testemunham alguns fenómenos de evolução em curso, marcada pela coexistência da forma tradicional e da forma inovadora. O sistema apresenta variação e as formas tradicionais conservadoras serão muitas vezes substituídas pelos usos inovadores. Tal como agora, há diversificação linguística e variação em curso com coexistência de formas antigas e novas. O texto de $O s$ Lusíadas é um exemplo de texto do período clássico sistematicamente referido como contendo arcaísmos e plebeísmos. O que se evidencia é a convivência do léxico tradicional e do léxico clássico. E é também um dos primeiros textos em que se observa uma forte hierarquização de predicados (caraterística que, ainda não há muito tempo, propiciava o exagero da sua utilização na aula para a 'divisão de orações'). A construção sintática do período clássico foi tão inovadora como a inovação lexical latinizante.

E é neste contexto que se integra a formação dos superlativos em -íssimo, que só surge na língua comum a partir do século XVI. Na análise de excertos de Os Lusíadas, texto em que é muito frequente a presença de superlativos em -íssimo, este traço pode ser encarado pelo leitor moderno como normal, porque não se apercebe empiricamente de que é uma inovação recente na língua e de que Os Lusíadas poderá ser o primeiro texto em português em que tal frequência de uso ocorre. Trata-se de um texto particular, de uma tradição discursiva muito específica. Muito clássico e, nesse sentido, muito inovador. O estudo dos textos deve ser marcado por profundidade histórica, dando conta da espessura temporal, o que revela uma sincronia movediça, com variação em curso.

\section{6 - Conclusão}

Retomo, para concluir, o que já referi no início sobre a inseparabilidade entre as dimensões informativa e formativa da reflexão sobre variação e mudança linguísticas.

A correta e adequada análise, explicitação e transmissão de conteúdos que estão tradicionalmente aliados à variação histórica da língua não são os únicos aspetos que beneficiam da informação adquirida pelos futuros professores sobre o fenómeno da variação linguística. Para além desta 
dimensão informativa, o conhecimento dos conceitos e metodologias da linguística da variação pode ter uma importante dimensão formativa, já que faculta ao professor uma perceção e interpretação de diversos fenómenos, quer em diacronia quer em sincronia. Esta perceção do 'fazer-se' contínuo da língua favorece igualmente a compreensão e um adequado enquadramento de fenómenos de variação em curso no português atual.

Um outro aspeto formativo assinalável do conhecimento da variação histórica da língua consiste na compreensão da relação estreita da variação diacrónica com a variação em geral e do processo de formação das variedades do Português (europeias e não-europeias) marcado por condicionamentos históricos diversos que explicam a sua diferente forma. $\mathrm{O}$ contraste entre normas diferentes da língua pode ser perspetivado através da análise de percursos evolutivos históricos.

Acresce que o conhecimento profundo do fenómeno da variação terá certamente repercussões na atitude do professor perante as produções horizontal e verticalmente marcadas e diferenciadas dos seus alunos. A compreensão do fenómeno da variação e da sua origem histórica retira parte da reação subjetiva e dos juízos de valor do falante comum porque os filtra através da objetividade científica. E pode motivar uma atitude avaliativa de procura de descrição e de explicação da múltipla variação diatópica, diastrática e situacional da língua capaz de complementar e enriquecer a atitude normativa e corretiva que é inseparável e definidora da situação de ensino.

Assim, creio poder resumir os diversos contributos que o trabalho com as sincronias do passado pode trazer aos professores de português e aos seus alunos em dois pontos essenciais: (1) conhecer a especificidade de estados históricos do idioma e da sua evolução e (2) alargar o conhecimento ou a compreensão do estado atual da língua, tornando o presente mais claro, ou perspetivado de outra forma em diversas direções de variação e de evolução.

A fundamentação teórica servirá de base a uma prática pedagógica reflexiva. A vocação explicativa da linguística histórica possibilita ao professor de língua materna a aquisição de uma competência plural que se concretiza não só como conhecimento de fenómenos do passado, como também como uma melhor compreensão do presente.

\section{REFERÊNCIAS}

Barros, C. 1997. História da Língua / Ensino da Língua. Revista da Faculdade de Letras do Porto, Línguas e Literaturas. II ${ }^{a}$ Série, XIV: 81-99.

Cardeira, E. 2005. Entre o Português Antigo e o Português Clássico. Lisboa: INCM - Imprensa Nacional Casa da Moeda.

Castro, I. 2006. Norma linguística e ensino do português. Caderno Escolar. Pensar a escola. 3: 30-36. 
Castro, I. 1989. História da Língua/Ensino da Língua. Actas do Congresso sobre a Investigação e Ensino do Português (Lisboa, 1987). Lisboa: ICALP, 95-104.

Gil Vicente. Auto da Alma. Porto: Porto Editora. s/d.

Magne. A. (Ed.). 1955. A Demanda do Santo Graal. (3 vols.) Rio de Janeiro: Imprensa Nacional.

Martins, A. M. 2002. Mudança sintáctica e História da Língua Portuguesa. In: B. Head; J. Teixeira; A. Sampaio Lemos; A. Leal de Barros; A. Pereira (Eds.). História da Língua e História da Gramática. Actas do Encontro. Braga: Universidade do Minho - Centro de Estudos Humanísticos, 251-297.

Paiva, M. H. 2001. Para conceber a língua na sua plasticidade: o contributo da História da Língua Portuguesa. In: A Linguística na formação do professor de português. Porto: FLUP, 153-162.

Teyssier, P. 1959. La langue de Gil Vicente. Paris: Klincksieck.

Teyssier, P. 2005. A língua de Gil Vicente. (Trad.). Lisboa: INCM Imprensa Nacional Casa da Moeda. 